\title{
Routine angiographic follow-up for left main percutaneous coronary intervention: Back to the old times?
}

\author{
Marcelo Sanmartin ${ }^{1}$, Ramesh Daggubati ${ }^{2}$ \\ ${ }^{1}$ Hospital Universitario Ramon y Cajal, Carretera Colmenar Viejo, Madrid, Spain \\ ${ }^{2}$ Interventional Cardiology Fellowship, NYU Winthrop Hospital, Mineola, NY, USA
}

\begin{abstract}
Article p. 582
Routine 6-month angiographic follow-up was common practice back in the 90 's due to relatively high rates of significant restenosis. Back then, the rate of repeated tar-
\end{abstract} get vessel revasculariza-

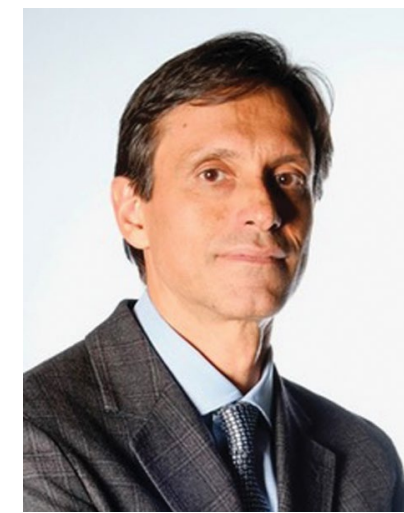

tion (TVR) could be as high as $30-40 \%$ in specific patient subsets, such as diabetics, long lesions or small vessels [1]. Invasive imaging is also a necessary part of the comprehensive evaluation of new devices and coronary intervention strategies, which have clearly helped the scientific community to bring down target vessel failure rates to one-digit figures. However, the systematic performance of repeated catheterization in asymptomatic, ischemia-free patients, undoubtedly leads to more interventions, the so called "oculostenotic reflex", without clear reduction in myocardial infarction or cardiovascular mortality [2,3]. But, is this also true for patients with left main or last remaining vessel percutaneous coronary intervention (PCI)?

In this issue of "Cardiology Journal", Aurigemma et al. [4] present interesting results from a retrospective study evaluating the impact of routine angiographic follow-up after successful PCI of unprotected left main stenoses. Approximately $90 \%$ of the 190 patients were treated with a 1 -stent technique and index procedures were performed with intravascular imaging in roughly 1 out of 4 cas-

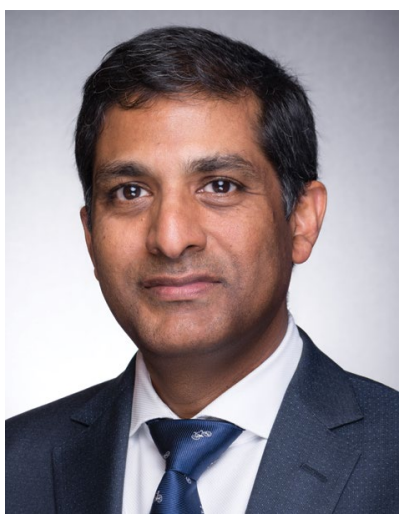

es. Despite interventionalists' recommendations to perform routine 6 - to 9 -month catheterizations in all patients, it was not done in $48 \%$ of those eligible cases due, most likely, to patient and physician preference.

As expected, study groups had some important differences at baseline: patients in the clinical follow-up group tended to be older (although not a statistically significant difference), with also a trend to a higher rate of renal failure and with more prior myocardial infarctions. Patients in the angiographic follow-up group were more commonly treated with a 2 -stent technique, although rates of final kissing-balloon were rather similar (65\%). The main finding of this study is that routine angiographic group had $3 \times$ higher TVR rates, but more importantly cardiac mortality were significantly lower at a mean follow-up of 35 months.

Different groups have tried to analyze the impact of systematic angiographic follow-up after sucessful left main PCI [5-7]. In contrast to the study of Aurigemma et al. [4], other Italian investigators, looking into a similar retrospective database of 198 patients with left-main treated between 2002 and 2007 , found that routine angiographic followup did not reduce myocardial infarction or cardiac death [5]. In a larger multicenter registry enrolling 1267 patients with left main treated with secondgeneration drug-eluting stent (DES), 440 patients

Address for correspondence: Marcelo Sanmartin, Director, Acute Coronary Syndrome Process, Hospital Universitario Ramon y Cajal, Carretera Colmenar Viejo, Madrid, Spain, 28034, e-mail: msanfer@me.com

Ramesh Daggubati, MD, FACC, FSCAI, Associate Chief of Cardiology, Director of Interventional Cardiology Fellowship, NYU Winthrop Hospital, Mineola, NY 11030, USA, e-mail: daggur@yahoo.com 
were selected by propensity score matching taking into consideration clinical and procedural variables and compared planned angiographic follow up with clinical only follow up [6]. After a median follow up of 16 months, the rates of all cause and cardiovascular death were significantly lower in the angiographic group (6\% vs. $14 \%, \mathrm{p}=0.01$ and $3 \%$ vs. $6 \%, \mathrm{p}=0.04)$. The rates of TVR were higher ( $15 \%$ vs. $5 \%, \mathrm{p}<0.001$ ), although this is clearly a worthy price to pay if it leads to reduced mortality.

Routine angiography was not mandated in the SYNTAX and EXCEL trials. These 2 studies have shown that left main PCI was equivalent to coronary artery bypass grafting (CABG) in Syntax scores less than $32[7,8]$. Recently published ReACT study from Japan, a randomized clinical trial of 700 patients, has shown an inconclusive difference in outcomes at 5 years between routine angiography and clinical follow up in the left main subgroup due to small simple size [9].

Retrospective studies have important limitations that should be considered before embracing the conclusion that one should re-catheterize all asymptomatic and ischemia-free patients with left main PCI. Most important, there are relevant baseline differences between study groups, not always corrected by multivariate analyses. Probably, clinicians felt more relutanct to send asymptomatic elderly patients, with renal failure and poorer left ventricular function for routine catheterization. These patients are much more prone to present severe complications, not always avoidable by treating restenosis, such as heart failure, sepsis, or arrhythmic sudden death. Second, we have no data on how this "clinical only" follow up was done. It could have been only simple office consultations with no intention to look for non-invasive signs of ischemia or left ventricular dysfunction. In that case, physicians could have missed an opportunity to perform a control angiography and prevent some of the events that might have ultimately lead to a worse prognosis. What would be the difference between the two groups if systematic imaging stress tests (or maybe also cardiac computed tomography) were performed 4-6 months after index revascularization in "clinical-only" patients?

Another practical issue is the timing of angiographic follow up. The rationale for re-catheterization after a 6-month interval is based on typical patterns of restenosis after bare-metal stent implantation [1]. However, although a 6 or 9 month interval seems adequate in many cases of side-branch or focal in-stent restenosis, other cases of late "catch-up" phenomenon or neoatherosclerosis occur $>1-2$ years after first and second generation DES and would be missed in this control angiography [10]. In addition, late or very-late stent thrombosis are better avoided by optimal stent deployment, in most cases based on intravascular imaging during the index procedure, and probably can not be prevented by performing routine 6-9 months angiographic follow up.

So, what are the main implications of this study to clinical practice? Current guidelines have been recently issued and grant a IIb recommendation to control angiography in asymptomatic patients with high-risk PCI, including unprotected left main [11]. The American College of Cardiology Foundation/American Heart Association/Society for Cardiovascular Angiography and Interventions (ACCF/AHA/SCAI) guidelines removed a previously class IIA recommendation of routine angiography in 2011 PCI guidelines [12]. Now that better stents are available and experience in treating left main lesions with PCI has been gained, optimal long-term results must be persued, at least equivalent to those achieved with arterial grafts. Thus, randomized studies are needed to definitively solve animportant question of what is the best follow-up strategy in this previously CABG-exclusive disease. Until then, patients should at least be provided with an optimal medical treatment, a close follow-up including a low threshold to repeat catheterization, non-invasive imaging including a stress test, and perhaps routine angiography in some high-risk cases.

\section{Conflict of interest: None declared}

\section{References}

1. Jukema JW, Verschuren JJW, Ahmed TAN, et al. Restenosis after PCI. Part 1: pathophysiology and risk factors. Nat Rev Cardiol. 2011; 9(1): 53-62, doi: 10.1038/nrcardio.2011.132, indexed in Pubmed: 21912414.

2. ten Berg JM, Kelder JC, Suttorp MJ, et al. Influence of planned six-month follow-up angiography on late outcome after percutaneous coronary intervention: a randomized study. J Am Coll Cardiol. 2001; 38(4): 1061-1069, indexed in Pubmed: 11583883.

3. Uchida T, Popma J, Stone GW, et al. The clinical impact of routine angiographic follow-up in randomized trials of drug-eluting stents: a critical assessment of „oculostenotic” reintervention in patients with intermediate lesions. JACC Cardiovasc Interv. 2010; 3(4): 403-411, doi: 10.1016/j.jcin.2010.01.010, indexed in Pubmed: 20398868.

4. Aurigemma C, Burzotta F, Porto I, et al. Clinical impact of routine angiographic follow-up after percutaneous coronary interventions on unprotected left main. Cardiol J. 2018; 25(5): 582-588, doi: 10.5603/CJ.a2018.0092. 
5. Biondi-Zoccai GGL, Giraudi E, Moretti C, et al. Impact of routine angiographic follow-up after percutaneous coronary drug-eluting stenting for unprotected left main disease: the Turin Registry. Clin Res Cardiol. 2010; 99(4): 235-242, doi: 10.1007/s00392-0090112-3, indexed in Pubmed: 20047051.

6. D'Ascenzo F, Iannaccone M, Pavani M, et al. Planned angiographic control versus clinical follow-up for patients with unprotected left main stem stenosis treated with second generation drug-eluting stents: A propensity score with matching analysis from the FAILS (failure in left main with second generation stents-Cardiogroup III Study). Catheter Cardiovasc Interv. 2017 [Epub ahead of print], doi: 10.1002/ccd.27408, indexed in Pubmed: 29130573.

7. Morice MC, Serruys PW, Kappetein AP, et al. Five-Year outcomes in patients with left main disease treated with either percutaneous coronary intervention or coronary artery bypass grafting in the synergy between percutaneous coronary intervention with taxus and cardiac surgery trial. Circulation. 2014; 129(23): 2388-2394, doi: 10.1161/circulationaha.113.006689.

8. Stone G, Sabik J, Serruys P, et al. Everolimus-eluting stents or bypass surgery for left main coronary artery disease.
N Engl J Med. 2016; 375(23): 2223-2235, doi: 10.1056/nejmoa1610227.

9. Shiomi H, Morimoto T, Kitaguchi S, et al. The ReACT Trial. Randomized Evaluation of Routine Follow-up Coronary Angiography After Percutaneous Coronary Intervention Trial. JACC: Cardiovascular Interventions. 2017; 10(2): 109-117, doi: 10.1016/j. jcin.2016.10.018.

10. Andreou I, Stone PH. In-stent atherosclerosis at a crossroads: neoatherosclerosis ... or paleoatherosclerosis? Circulation. 2016; 134(19): 1413-1415, doi: 10.1161/CIRCULATIONAHA.116.025129, indexed in Pubmed: 27821417.

11. Neumann FJ, Sousa-Uva M, Ahlsson A, et al. 2018 ESC/EACTS Guidelines on myocardial revascularization. Eur Heart J. 2018 [Epub ahead of print], doi: 10.1093/eurheartj/ehy394, indexed in Pubmed: 30165437.

12. Levine GN, Bates ER, Blankenship JC, et al. 2011 ACCF/ /AHA/SCAI Guideline for Percutaneous Coronary Intervention: a report of the American College of Cardiology Foundation/ /American Heart Association Task Force on Practice Guidelines and the Society for Cardiovascular Angiography and Interventions. Circulation. 2011; 124(23): e574-e651, doi: 10.1161/ /CIR.0b013e31823ba622, indexed in Pubmed: 22064601. 